bond $\left(1600\right.$ and $\left.1540 \mathrm{~cm}^{-1}\right)$ which may be due to a substituted furan linkage.

The authors wish to express their sincere thanks to Prof. Y. Sumiki for his kind guidance in performing this study.

\author{
References \\ 1) Y.Sumiki, J.Agr.Chem.Soc.Japan, 5,513 (192)). \\ 2) Y.Sumiki, J.Agr.Chom.Soc.Japan, 7,819 (1931). \\ 3) J.H, Tumer et al,, Anal.Ch:m., 26, 898 (1954). \\ Sumiki Laboratory, Department of \\ Agricultural Chemistry, Faculiy of \\ Agriculture, University of \\ Tokyo, Tokyo
}

[Received; Dec. 20, 1954]

\title{
14. Studies on Fungisporin. Part 2.
}

\author{
By Kohei MrYaO
}

\begin{abstract}
Fungisporin was subjected to acid and alkali hydrolysis and converted to amino acids. These amino acids were identified to be the two amino acids, L-phenylalanine and L-valine. From the results of the quantitative determination of each amino acid and infrared spectrum of the fungisporin, it was revealed that the fungisporin is a polypeptide composed of the same moles of $\mathrm{L}^{-}$ phenylalanine and $\mathrm{L}$-valine.
\end{abstract}

In the previous paper ${ }^{1)}$, it was reported that fungisporin, isolated from spores of several species of Penicillium and Aspergillus, was assumed to be a high molecular substance somewhat similar to a simple protein with respect to solubility, infrared spectrum, and the formation of the primary amines as its degradation products by heating with conc. hydrochloric acid. The present paper deals with the constituents of the acid and alkali hydrolyzates of the fungisporin as well as its molecular structure.

From the degradation product by acid hydrolysis, two amino acids were separated through their Cu-salts and were identified as DL-phenylalanine and DL-valine by the mixed melting points with the authentic specimens and from elementary analyses, indicating that racemization occurred during hydrolysis.

Moreover, paper chromatography of the acid hydrolyzate of fungisporin showed only two spots corresponding to phenylalanine and valine, and no other spots appeared. Furthermore, no other amino acid was detected by various qualitative analyses and paper chromatography of the alkali hydrolyzate, in an attempt to resolve the question of the presence of tryptophane which was unstable in the acid hydrolysis.

The experimental formula presented in the previous paper for the fungisporin should be corrected according to 
recent analytical data and from results described above to the formula, $\left(\mathrm{C}_{14} \mathrm{H}_{18} \mathrm{O}_{2} \mathrm{~N}_{2}\right)_{\mathbf{x}}$

The result of the quantitative determination of $\alpha$-amino nitrogen in the hydrolyzate showed that all the nitrogen of fungisporin was $\alpha$-amino nitrogen. To determine each amino acids component of fungisporin, the method of A.H. Gordon, A.J.P. Martin and L.M. Synge ${ }^{2)}$ was applied, and it was proven that fungisporin was composed of the same number of moles of these two amino acids and had no other residue. The above formula was completely agreed with not only this result, but also that of the derived by connecting same mole of valine and phenylalanine through simple amide linkage to give polypeptide having negligible end groups.

As to the optical configuration of the component amino acids, it was assumed to be the L-form because of the agreement of the values obtained on comparative bioassays of the hydrolyzate of fungisporin and a control which was subjected to the same procedure for the pure L-form amino acids.

The infrared absorption spectrum of a nujol mull of fungisporin is shown in Fig. 1.

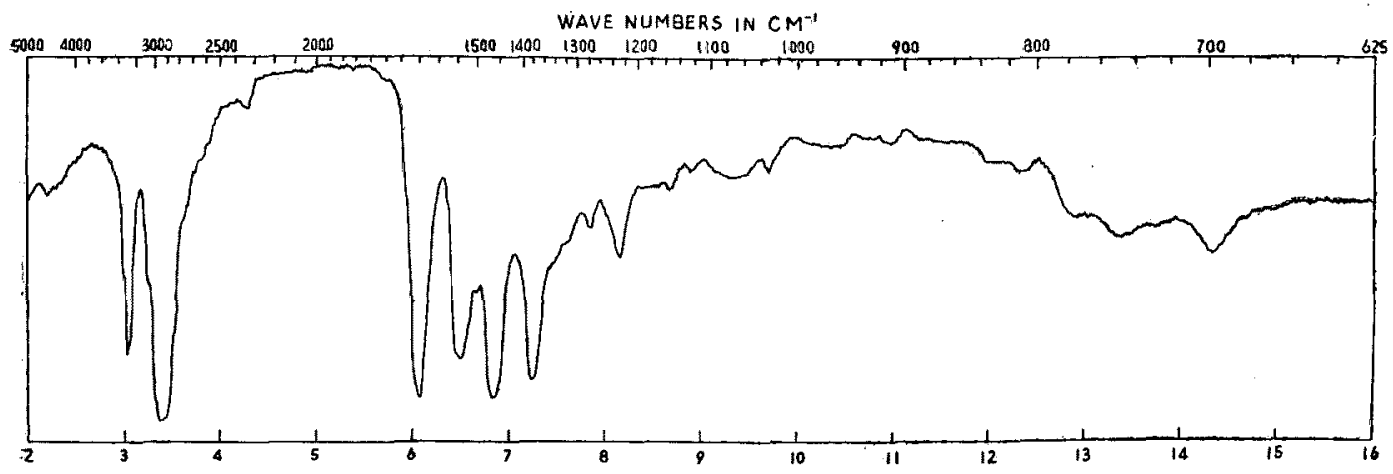

Fig. 1.

The presence of the bands at 3300 , $3100,1640,1540,1220$ and $700 \mathrm{~cm}^{-1}$ shows definitely that fungisporin is the linear polypeptide type compound and not the diketopiperazine type.

The next step in the study of the structure of this peptide will involve partial hydrolysis in order to determine the sequence of the amino acids, and to determine its molecular weight.

These are being undertaken at present. It is interesting to note the fact that this fungisporin sublimes, despite its being a true peptide and not diketopiperazine type.

Further research of strains containing fungisporin is going on, and the species which have been found to contain the fungisporin at present are the following (concluding the species reported in the previous paper):

Penicillum: notatum, chrysogenum, citrinum, claviform, purpurogenum, herquei, frequentaus, roseo-purpureum, brevicaule.

Aspergillus : niger, vercicolor. 


\section{Experimental}

1. Identification of phenylalanine and valine as the component amino acids.

As described in the previous paper from the degradation product of fungisporin by heating with conc. $\mathrm{HCl}$ at $200^{\circ}$ for several hrs., a primary amine $\mathrm{C}_{8} \mathrm{H}_{13} \mathrm{O}_{2} \mathrm{~N}$, m.p. $249^{\circ}$ (decomp) was obtained by recrystallization. This crystal gave a positive ninhydrin reaction and its benzenesulfonyl derivative. The above product was titrated potentiometrically by $\mathrm{N} / 20 \mathrm{NaOH}$ and $\mathrm{N} / 20$ $\mathrm{HCl}$, using the Beckmann $\mathrm{pH}$ meter G-type. Its titration curve showed the buffer action in both acidic and basic sides, and the addition of formalin made it acidic. These phenomena indicate the substance to be a mixture of amino acids.

$150 \mathrm{mg}$ of this substance was boiled with freshly prepared copper hydroxide and filtered while hot. On cooling, the sparlingly soluble Cu-salt precipitated as light blue leaflets and filtered off. The precipitate was followed by washing with water, recrystallization from hot water three times, and dried (96 mg) (1). The filtrate was evaporated to dryness, and extracted with methanol and then water. Concentrating these extracts, the blue leaflets were preciptated by the addition of ethanol from the each extract. These preciptates were, recrystallized and dried: methanol soluble (11) (6 mg), water soluble (111) (63 mg).

The Cu-salts were analyzed and freed from the copper by treating with hydrogen sulfide but the methanol soluble Cu-salt quantity was too little and was completely used up by analysis.

Analytical figures of (1) agree with the Cu-salt of phenylalanine, Data of (11) and (111), also agreed with that of Cu-salt of valine.

Calcd. for $\left(\mathrm{C}_{9} \mathrm{H}_{10} \mathrm{O}_{2} \mathrm{~N}\right)_{2} \mathrm{Cu}: \quad \mathrm{C}, 55.21$ $\mathrm{H}, 5.12 \mathrm{~N}, 7.21$ Ash, 20.02

Found. C, $54.95 \mathrm{H}, 4.48 \mathrm{~N}, 7.20$ Ash, 20.11

Calcd. for $\left(\mathrm{C}_{5} \mathrm{H}_{10} \mathrm{O}_{2} \mathrm{~N}\right)_{2} \mathrm{Cu}: \mathrm{C}, 40.65$ $\mathrm{H}, 6.77 \mathrm{~N}, 9.49$ Ash, 26.9

Found. of (11) C, $40.94 \mathrm{H}, 6.06 \mathrm{~N}$, 9.10 Ash, 26.7

Found. of (111) C, $41.02 \mathrm{H}, 6.58 \mathrm{~N}$, $9.32 \mathrm{Ash}, 26.8$

\section{a) Identification of DL-phenyl- alanine.}

The free amino acid obtained from the slightly soluble $\mathrm{Cu}$-salt was given the experimental formula $\mathrm{C}_{9} \mathrm{H}_{12} \mathrm{O}_{2} \mathrm{~N}$, from the analytical data which corresponded to that of phenylalanine. The benzoyl derivative of this amino acid, followed by recrystallization from water and ethanol showed m.p. $186^{\circ}$. This melting point was not depressed by an admixture of benzoyl DL-phenalalanine (m.p. $187^{\circ}$ ). Also the m.p. of the toluenesulfonyl derivative of this amino acid was $134^{\circ}$ and was not depressed by mixing with the corresponding compound of DL-phenylalanine. Calcd. for $\mathrm{C}_{9} \mathrm{H}_{11} \mathrm{O}_{2} \mathrm{~N}: \mathrm{C}, 65.5 \mathrm{H}, 6.67 \mathrm{~N}$, 8.49. Found. C, $65.21 \mathrm{H}, 6.28 \mathrm{~N}$, 8.46 .

b) Identification of DL-valine.

The analytical figures agreed with that of valine. Calcd. for $\mathrm{C}_{5} \mathrm{H}_{11} \mathrm{O}_{2} \mathrm{~N}$ : $\mathrm{C}, 51.26 \mathrm{H}, 9.46 \mathrm{~N}, 11.95$. Found. C, $51.47 \mathrm{H}, 9.87 \mathrm{~N}, 11.24$.

The mixed melting point of this. benzoyl derivative (m.p. 132 $)$ with corresponding derivative of DL-valine was not depressed. The methanol soluble Cu-salt was assumed to be a salt of optical active valine by its solubility 
and analytical data.

c) Identification by paper chromatography.

Paper chromotography was applied directly to the acid hydrolyzate emplying the following solvents: a mixture of butanol-acetic acid-water $(4: 1: 5)$, or liq. phenol satud. with $0.3 \% \mathrm{NH}_{3}$ water, or a mixture of 2,4,6-collidine2,6-lutidine-water (1:1:1). The result was that no other amino acids were found than the two mentioned above. In alkali hydrolysis, fungisporin showed extrordinary resistance to the hydrolysis so that a considerably amount of it remained unchanged in the hydrolyzate with $25 \%$ barium hydroxide soln. at $150-155^{\circ}$ for 6 days. The presence of tryptophane was not detected when this hydrolyzate was tested by the following methods: paper chromatography, Hopkins-Cole reaction, ${ }^{3)}$ Neubauer-Rhode reaction, ${ }^{4)}$ Folin-Denis reaction ${ }^{5)}$ etc.

\section{Experimental formula for fun- gisporin.}

Repeating the elemental analysis of fungisporin gave the corrected analytical data and resulted in the establishment of new experimental formula, $\left(\mathrm{C}_{14} \mathrm{H}_{18} \mathrm{O}_{2} \mathrm{~N}_{2}\right)$.

\begin{tabular}{cccc}
\multicolumn{4}{c}{ Analytical data of fungisporin. } \\
$\mathrm{C} \%$ & $\mathrm{H} \%$ & $\mathrm{~N} \%$ & \\
68.38 & 7.33 & 11.38 & Found. (sample purified by sublimation 2 times) \\
68.30 & 7.29 & 11.33 & Found. (sample purified by sublimation 3 times) \\
68.29 & 7.37 & 11.35 & Calcd. for $\mathrm{C}_{14} \mathrm{H}_{18} \mathrm{O}_{2} \mathrm{~N}_{2}$
\end{tabular}

This formula agrees with the figure of of phenylalanine and valine. the dehydrated condensation product

$$
\begin{aligned}
& \text { fungisporin phenylalanine Valine } \\
& \left(\mathrm{C}_{14} \mathrm{H}_{18} \mathrm{O}_{2} \mathrm{~N}_{2}\right) x=x \mathrm{C}_{9} \mathrm{H}_{41} \mathrm{O}_{2} \mathrm{~N}+x \mathrm{C}_{5} \mathrm{H}_{11} \mathrm{O}_{2} \mathrm{~N}-2 x \mathrm{H}_{2} \mathrm{O}
\end{aligned}
$$

III. Quantitative analysis of the component amino acids.

Since it was found out that fungisporin could be hydrolyzed producing almost no humin material below $140^{\circ}$, and that at the temperature below $110^{\circ}$ it scarcely hydrolyzed with $36 \% \mathrm{hy}$ drochloric acid, the hydrolysis was carried out at $140-130^{\circ}$ for 4-7 days in many cases. Preparation of sample: $49.16 \mathrm{mg}$ of fungisporin was hydrolyzed with $10 \mathrm{cc}$ of $36 \% \mathrm{HCl}$ at $140-130^{\circ}$ for 6 days followed by evaporation to dryness, dissolved in water, filtered to remove traces of undissolved residue and filled up to $10 \mathrm{cc}$ with water.

a) $\alpha$-amino nitrogen determination.

$0.5 \mathrm{cc}$ of above solution was applied to the determination of $\alpha$-amino nitrogen by Van Slyke method and found to be $0.1346 \mathrm{mg}$ (corresponding to $96.2 \%$ theoretical value, calculated as $\mathrm{N} / \mathrm{C}_{14} \mathrm{H}_{18} \mathrm{O}_{2} \mathrm{~N}_{2}+2 \mathrm{H}_{2} \mathrm{O}$ ). This value indicated that all nitrogen in fungisporin molecule was $x$-amino nitrogens.

b) Determination of component amino acids.

(1) By the method of A.H. Gordon, A.J.P. Martin, and L.H. Synge.

Satisfactory results were obtained by this method, using Mallinckrodt silicic acid for the control test. $5 \mathrm{cc}$ of the above solution was evaporated to dryness and acetylated according to the above mentioned method. This acetylated hydrolyzate was chromatographed and each of the separated fractions 
was titrated as described in the papers of the above mentioned authors. $5 \mathrm{~g}$ of silicic acid (Mallinckrodt analytical reagent) were colored by adding $3 \mathrm{ml}$ $0.1 \%$ aq. methyl orange soln. to it, and then suspended in chloroform containing $3 \%$ butanol. This was placed into a chromatogram tube having an internal diameter $1 \mathrm{~cm}$. The following results were obtained;

phenylalanine: $0.0785 \mathrm{mM}(12.95 \mathrm{mg}) 96.5 \%$ Calcd. as fungisporin took 2 mole of $\mathrm{H}_{2} \mathrm{O}$

valine $\quad: 0.0777 \mathrm{mM}(9.07 \mathrm{mg}) 95.2 \%$ per each dipeptides by hydrolysis

(2) By paper chromatography.

Amino acids of the hydrolyzate described were also determined by paper chromatography, employed the method of maximum color density. ${ }^{6)}$ Briefly, the procedures were as follows Paper: Toyo filter paper No. 51 $(2 \times 40 \mathrm{~cm})$ (was satisfactory). Solvent : butanol-HAc-water (4:1:5) (upper layer). 2.51 of each of the standard amino acid solutions of various concentrations, $1 \mathrm{~mm} / \mathrm{l}, 2 \mathrm{mM} / \mathrm{l}, 3 \mathrm{mM} / \mathrm{l}$, $4 \mathrm{mM} / \mathrm{l}, \quad 5 \mathrm{mM} / \mathrm{l}, \quad 6 \mathrm{mM} / \mathrm{l}, \quad 7 \mathrm{mu} / \mathrm{l}$, $7 \mathrm{mM} / \mathrm{l}, 9 \mathrm{~m} \mathrm{r} / \mathrm{l}, 10 \mathrm{mM} / \mathrm{l}$, were spoted on a strip and chromatographed, followed by developing the color with ninhydrin soln. Maximum color densities of the spots of these chromatograms were measured in percent transmission to blank paper by the densitometer, which was made in our laboratory for paper chromatography and had a slit of $2 \mathrm{~mm} \times 6 \mathrm{~mm}$ and filter of $570 \mathrm{~m} \mu$. Standard curves, which were prepared by plotting the max. density of each spot against its concentration in the semi-logarithmic paper, were straight. The concentrations of amino acids to be tested were determined from the max. color densities of their spots by comparing them with the standard curve of the corresponding amino acid. From this experiment the following results were obtained. (average)

phenylalanine: $28.2 \mathrm{mg}$ in this hydrolyzate. $92 \%$

valine : $20.8 \mathrm{mg},$, , , ,, $95.5 \%$

(recovery was calcd. from the fact that fungisporin takes 2

moles of water per dipeptide by hydrolysis.)

\section{c) Bioassay. ${ }^{7}$}

As it is almost impossible to carry out the hydrolysis without any racemization, I compared the results of bioassays applied to fungisporin hydrolyzate to a mixture of the same number of moles of L-phenylalanine and Lvaline which was heated with $\mathrm{HCl}$ under the same conditions as the hy- drolysis in order to determine the optical configuration of the component amino acids of fungisporin.

$21.45 \mathrm{mg}$ of fungisporin and a mixture of $12.38 \mathrm{mg}$ L-phenylalanine and $9.08 \mathrm{mg} \mathrm{L}$-valine were hydrolyzed with $36 \% \mathrm{HCl}$ at $140-130^{\circ}$ for 6 days. Results of bioassays, using Lactobacillus arabinosus, were as follows.

$$
\begin{aligned}
& \text { fungisporin: Lrphenylalanine } 7.36 \mathrm{mg} \text { in } 10 \mathrm{cc} \text { hydrolyzate } 51.2 \% \\
& \text { Lrvaline } \quad 6.12 \mathrm{mg},,,, \quad,, \quad 59.6 \% \\
& \text { control : L-phenylalanine } 6.6 \mathrm{mg},,,, \quad,, \quad 53.2 \% \\
& \text { L-valine } \quad 5.5 \mathrm{mg} \mathrm{,,} \mathrm{,,},, \quad 60.1 \%
\end{aligned}
$$

The author wishes to express his proper derection and very kind guithanks to Prof. Dr. Y. Sumiki for his dance. I am indebted to Wakamoto 
Seiyaku, Ltd. for the help I received in the preparation of samples; to Dr. T. Shimanouchi and Mr. T. Miyazawa of Mizushima Laboratory, Department of Chemistry, University of Tokyo, for the infrared analysis and its interpretation; to Mr. S. Abe of Sakaguchi Laboratory, Department of Agricultural Chemistry, University of Tokyo, for his contribution of strains and to $\mathrm{Mr}$. G. Tamura and Mr. Y. Suzuki of Sakaguchi Laboratory for their kind guidance of bioassay; The author is also grateful to Mr. J. Hattori and Mr. K. Higuchi for their cooperation in carrying out these experiments.
This work was supported in part by a grant from the Scientific Fund of the Ministry of Education to which the author is also indebted.

\section{Literature}

1) Y. Surniki and K. Miyao: J.Agr. Cbem.Soc. of Japan 26, 27 (1952).

2) A.G. Gordon et al. Biochsm. J. 37,79(1943)

3) Hopkins-Cole: Proc. Roy. Soc., 68, 23(1901).

4) Folin-Loony : J. Biol. Cbem., 51, 421 (1922).

5) E. Rhode: Z. Physiol. Chem, 44, 161 (1905).

6) R.J. Block: Anal. Cbem., 22, 1327 (1950).

Paper Chromatography, Academic Press, (1952) p.44.

7) G. Tamura et al.: J.Agr.Chem.Soc. 'f Japan, 26, 464, 480 (1952).

Sumiki Laboratory, Department of Agricultural Chemistry, University of Tokyo, Tokyo

[Received, Dec. 20, 1954] 